\title{
Feasibility of primary human cell cultures as a model for adamantinomatous craniopharyngioma research: Evidence from RNA-Seq analysis
}

\author{
PEI-DONG ZHANG* ${ }^{*}$ CHAO-HU WANG ${ }^{*}$, JUN FAN* ${ }^{*}$ JUN-XIANG PENG, JUN PAN, SONG-TAO QI and YI LIU \\ Department of Neurosurgery, Nanfang Hospital of Southern Medical University, Guangzhou, Guangdong 510515, P.R. China
}

Received March 9, 2018; Accepted November 21, 2019

DOI: $10.3892 / 01.2020 .11309$

\begin{abstract}
Adamantinomatous craniopharyngioma (ACP) is a benign epithelial tumor of the sellar region. Whether primary human cell cultures can be used as a stable research model has yet to be determined. The characteristics of three cultured craniopharyngioma primary cell (CPC) lines were identified using immunofluorescence. The culture duration for each CPC line was 10, 20 and 30 days. Cell lines and paired parental tumor tissues were subsequently analyzed using transcriptome sequencing (RNA-Seq). Transcriptomic differences between ACP tissues and CPC lines were compared. CPCs maintained the original epithelial lineage markers, including pan-cytokeratin and epithelial cell adhesion molecule. However, the Pearson's correlation coefficient of transcriptomes between each pair of CPC lines and ACP tissues decreased from 0.657 (cultured for 10 days) to 0.61 (cultured for 20 days) and further to 0.547 (cultured for 30 days). The number of differentially expressed genes between ACP tissues and CPCs was increased from 1,247 (cultured for 10 days) to 1,643 (cultured for 20 days) and then to 1,949 (cultured for 30 days). The results of Gene Set Enrichment Analysis demonstrated that the diversity of gene sets increased with longer culture time. Significant differences in the majority of signature gene sets were not observed between ACP tissues and CPCs, with the exception of keratinization phenotype [normalized enrichment score $(\mathrm{NES})=-2.02$, false discovery rate $(\mathrm{FDR})=0.0038]$ and epithelial cell phenotype $(\mathrm{NES}=-1.82, \mathrm{FDR}=0.032)$. Cell proliferation $(\mathrm{NES}=1.78, \mathrm{FDR}=0.028)$ and mitosis $(\mathrm{NES}=1.93$, $\mathrm{FDR}=0.012$ ) were enhanced in CPCs. Therefore, primary
\end{abstract}

Correspondence to: Dr Yi Liu or Dr Song-Tao Qi, Department of Neurosurgery, Nanfang Hospital of Southern Medical University, 1838 Guangzhou North Avenue, Guangzhou, Guangdong 510515, P.R. China

E-mail: 278679433@qq.com

E-mail: qisongtaosjwk@126.com

*Contributed equally

Key words: adamantinomatous craniopharyngioma, primary cell cultures, RNA-Seq, gene set enrichment analysis, model human cell cultures can be used as a suitable research platform for ACP, however further experiments are required.

\section{Introduction}

Adamantinomatous craniopharyngioma (ACP) is a rare epithelial tumor of the sellar region (1). As the tumor is adjacent to the hypothalamus-pituitary axis, craniopharyngioma is typically intractable (2). Therefore, gaining a better understanding of the molecular pathology of craniopharyngioma is of major importance for the development of targeted therapies to improve patient outcomes $(3,4)$.

With the extensive application of high-throughput omics in craniopharyngioma research, the understanding of the molecular pathology of the tumor has been further extended. Almost all patients with ACP have been reported to have mutations in exon 3 of the catenin $\beta 1$ (CTNNBI) gene (5). As a result, $\beta$-catenin cannot be degraded in the cytoplasm and is translocated to the nucleus, continuously activating the Wnt/ $\beta$-catenin pathway (6-8). Using the mRNA microarray gene expression analysis method, several pharmaceutical targets have been identified, which have been reported to be significantly and consistently upregulated in ACP compared with that in pituitary tumors and normal pituitary tissue (9). Previous studies have also indicated that other signaling pathways, including the epidermal growth factor (EGF), NOTCH, bone morphogenetic protein (BMP)/fibroblast growth factor (FGF) and Sonic hedgehog (Shh) pathways are involved in ACP tumorigenesis $(8,9)$.

In order to better understand this disease, several models of ACP have been established (5-8), ranging from primary cell cultures to transgenic mouse models. Two murine models (Sox2 $2^{\mathrm{CreERT} 2 /+}$; Ctnnb1 $1^{\text {lox(ex3)/+ }}$ and Hesx $1^{\mathrm{Cre} /+} ; \mathrm{Ctnnb}^{\operatorname{lox}(\mathrm{ex} 3) /+}$ ) resembling human ACP in the anterior pituitary were established $(10,11)$. On the other hand, craniopharyngioma primary cell (CPC) lines have the advantage of being derived from human tumors and can be used to screen pharmacological agents relatively easily; however, the tissue disruption required for cell culture means that the complex architecture of the ACP is lost (12). Furthermore, culture conditions cannot replicate microenvironmental signals to the tumor from the surrounding tissue. To the best of our knowledge, it has yet to be examined whether CPC culture can be used as appropriate model of tumor tissues.

It is unclear how much difference in transcriptome between cultured primary cells and tumor tissues of ACP. Therefore, 
the aim of this study was to investigate whether cultured primary cells in vitro can make a good simulation of tumors in vivo, and whether the effect of simulation is weakened with the prolongation of culture time.

\section{Materials and methods}

Tumor samples. A total of three ACP tumor samples were included in this study. Samples were obtained from three patients who underwent primary tumor resection at the Neurosurgery Department of Nanfang Hospital between May and July 2017. Three patients were all female, and their ages were 42, 56 and 59 years old. Tumor samples were collected during surgery and stored at $4^{\circ} \mathrm{C}$ until culture procedures were performed. All ACP tumor samples were pathologically confirmed by hematoxylin and eosin staining. The staining was performed at $25^{\circ} \mathrm{C}$ for $5 \mathrm{~min}$ with hematoxylin and $2 \mathrm{~min}$ with eosin. The diagnosis was made by two pathologists who were blinded to the conditions of the study. Written informed consent was provided by all subjects in accordance with the Declaration of Helsinki. The present study was approved by the local Ethics Committee of Nanfang Hospital, Southern Medical University.

Cell culture. ACP specimens were cultured as previously reported (13-15). Tumor tissues were washed in triplicate with PBS and then cut into fragments $\sim 5 \mu \mathrm{m}$. Tissues were digested with $0.25 \%$ trypsin for $40 \mathrm{~min}$, and DNase $(20 \mu \mathrm{g} / \mathrm{ml}$; Sigma-Aldrich; Merck $\mathrm{KGaA}$ ) was added for $5 \mathrm{~min}$ at $37^{\circ} \mathrm{C}$. Tumor cells were centrifuged at $300 \mathrm{x}$ g for $5 \mathrm{~min}$ in room temperature, resuspended and cultured at $37^{\circ} \mathrm{C}$ with $5 \% \mathrm{CO}_{2}$. For the first 3 days, the culture medium was DMEM-F12 (Gibco; Thermo Fisher Scientific, Inc.) with 20\% FBS, after which FBS concentration was decreased by $10 \%$ at each passage until it was zero. Finally, cells were cultured in serum-free medium with additional $5 \mu \mathrm{g} / \mathrm{ml}$ insulin (Sigma-Aldrich; Merck KGaA) and $10 \mu \mathrm{g} / \mathrm{ml}$ EGF (R\&D Systems, Inc.) as previously described (13-15). The anchorage velocity-dependent separation method was used to exclude mesenchymal cells (14).

Immunofluorescence. Cells were cultured at $37^{\circ} \mathrm{C}$ with $5 \% \mathrm{CO}_{2}$ in cover glass-bottomed dishes. At $24 \mathrm{~h}$, cells were washed with PBS and fixed in $4 \%$ paraformaldehyde for $30 \mathrm{~min}$ at $4^{\circ} \mathrm{C}$. Cells were then ruptured and blocked in $0.1 \%$ Triton X-100 and $5 \% \mathrm{BSA}$ at $25^{\circ} \mathrm{C}$ for $30 \mathrm{~min}$. Cells were incubated at $4^{\circ} \mathrm{C}$ overnight with primary antibodies, including pan-cytokeratin (pan-CK; dilution, 1:100; cat. no., ab7753; Abcam) and epithelial cell adhesion molecule (EpCAM; dilution 1:100, cat. no., ab32392; Abcam), followed by incubation at $25^{\circ} \mathrm{C}$ for $1 \mathrm{~h}$ with Alexa Fluor 488 anti-mouse or 594 anti-rabbit secondary antibody (dilution, 1:1,000; cat. nos. A-11001 and A-11012; Invitrogen; Thermo Fisher Scientific, Inc.). Nuclei were counterstained with DAPI (Sigma-Aldrich; Merck KGaA). Images were captured on an inverted LSM880 confocal system (magnification, x400; Zeiss AG).

Western blot analysis. Cells were lysed in RIPA Buffer (50 Mm Tris-HCl pH 8.0, 1 mM EDTA pH 8.0, 5 mM DTT, $2 \% \mathrm{SDS}$ ), and the protein concentration was determined using a
BCA assay (Beyotime Institute of Biotechnology). Total protein $(30 \mu \mathrm{g})$ was resolved using 10\% SDS-PAGE gel, electro-transferred to polyvinylidene fluoride membranes (Invitrogen; Thermo Fisher Scientific, Inc.) and blocked with 5\% non-fat dry milk at $25^{\circ} \mathrm{C}$ for $1 \mathrm{~h}$ in Tris-buffered saline (pH 7.5). Membranes were immunoblotted overnight at $4^{\circ} \mathrm{C}$ with rabbit monoclonal antibodies at a dilution of 1:1,000, including keratin 5 (cat. no., 25807), E-cadherin (cat. no., 3195), vimentin (cat. no., 5741) and GAPDH (cat. no., 2118), all purchased from CST Biological Reagents Co., Ltd. A HRP-conjugated anti-rabbit IgG antibody was used as the secondary antibody (dilution, 1:2,000; cat. no., 7074; CST Biological Reagents Co., Ltd.). The incubation was performed at $25^{\circ} \mathrm{C}$ for $1 \mathrm{~h}$. Signals were detected using enhanced chemiluminescence reagents (EMD Millipore). Signal intensities were obtained using ImageJ software (v1.51, National Institutes of Health).

RNA-Seq library preparation and sequencing. Total RNA was extracted from all three surgical specimens and the corresponding primary cells. The RNA concentration was measured using a Qubit ${ }^{\circledR}$ RNA Assay kit in a Qubit ${ }^{\circledR} 2.0$ Fluorometer (both from Thermo Fisher Scientific, Inc.), and RNA integrity was assessed using the RNA Nano 6000 Assay kit with the Bioanalyzer 2100 system (both from Agilent Technologies, Inc.) according to the manufacturer's protocol. A total of $3 \mu \mathrm{g}$ RNA per sample was used as the input material. Ribosomal RNA (rRNA) was removed using an Epicentre Ribo-zero ${ }^{\mathrm{TM}}$ rRNA Removal kit (Epicentre; Illumina, Inc.), according to the manufacturer's protocol. Subsequently, sequencing libraries were generated using rRNA-depleted RNA with the NEBNext ${ }^{\circledR}$ Ultra $^{\mathrm{TM}}$ Directional RNA Library Prep kit for Illumina ${ }^{\circledR}$ (New England BioLabs, Inc.) according to the manufacturer's protocol. PCR was performed with Phusion High-Fidelity DNA polymerase, Universal PCR primers and Index (X) Primer. Finally, the products were purified (AMPure XP system), and library quality was assessed on the Agilent Bioanalyzer 2100 system. Clustering of the index-coded samples was performed using a cBot Cluster Generation System with a TruSeq PE Cluster kit v3-cBot-HS (Illumina, Inc.). Following cluster generation, the libraries were sequenced on an Illumina Hiseq X-ten platform and 150-bp paired-end reads were generated (sequenced by Novogene Co., Ltd.).

Data analysis. Raw data of fastq format were firstly processed through in-house perl scripts. Clean data were obtained by removing reads containing adapter or poly-N and low-quality reads from the raw data. All downstream analyses were performed using the clean high-quality data. The reference genome index was built using Bowtie2 v2.2.8 software (16) and paired-end clean reads were aligned to the reference genome using HISAT2 software (v2.0.4) $(17,18)$. StringTie software (v1.3.1) (19) was used to calculate the fragments per kilobase of exon per million fragments mapped (FPKMs) of coding genes in each sample (20). Gene FPKMs were computed by adding the FPKMs of the transcripts in each gene group. Ballgown R package (21) was used to compare all transcripts across conditions and produces tables and plots of differentially expressed genes and transcripts. Transcripts with q-value $<0.05$ were 
designated as differentially expressed. Genes were ranked using the pre-ranked tool in Gene Set Enrichment Analysis (GSEA) (v3.0, Broad Institute). Gene sets were downloaded from the hallmark molecular signatures database (v6.1; Broad Institute) $(22,23)$.

Statistical analysis. Statistical analyses were performed using GraphPad Prism (v7.0 GraphPad Software, Inc.). The Pearson's correlation coefficient was used to assess the association between two groups. The results are presented as the mean \pm standard deviation. When calculating the expression value of signature genes, a two-tailed Student's t-test was performed to compare the means of two groups. Image J software (v1.51, National Institutes of Health) was used to process semi-quantitative analysis of the densitometry obtained from western blot experiments. All western blot and immunofluorescence experiments were performed in triplicate. One-way ANOVA was performed to compare the group means followed by Tukey's post hoc test. $\mathrm{P}<0.05$ was considered to indicate a statistically significant difference. No samples were excluded from the analyses.

\section{Results}

Morphological evolution of primary cells. The initial CPCs exhibited a paving stone-like appearance and spontaneously formed keratin pearls (Fig. 1A and B). With increased culture time and passages $(10,20$ and 30 days), cell morphology gradually changed from the initial epithelial irregular polygon shape to a spindle shape, and further stabilized in the latter form (Fig. 1C-F).

CPCs maintain the properties of epithelial cells. Pan-CK and EpCAM are classical epithelial markers (24). The expression of pan-CK and EpCAM was measured in cells cultured for 10 days (CPC1), 20 days (CPC2) and 30 days (CPC3) using immunofluorescence. The results demonstrated that pan-CK and EpCAM remained positively expressed as culture time increased (Fig. 1G). The epithelial properties of CPCs did not change even with prolonged culture time and increased passages.

Transcriptome differences between ACP tissues and CPCs. To analyze the characteristics of CPCs and identify whether they can be used as a stable research model, three pairs of CPCs and their parental ACP tissues were analyzed using RNA-Seq. Pearson's correlation coefficient was used to compare the consistency of the transcriptome between CPCs and ACP tissues. With increased cell culture time, the correlation coefficient decreased from 0.657 (CPC1) to 0.610 (CPC2) and then to 0.547 (CPC3) (Fig. 2A-C). This indicated that the difference of transcriptome between CPCs and ACP tissues increased with prolonged culture time.

The heat map revealed that the correlation coefficient was high (>0.8) for the three ACP tissues; however, as culture time increased, the transcriptome correlation coefficient between ACP tissues and CPCs decreased gradually. The correlation coefficient among CPC groups also decreased gradually with increased culture time (CPC3 vs. CPC2, 0.900; CPC3 vs. CPC1, 0.573; CPC2 vs. CPC1, 0.604) (Fig. 2D).
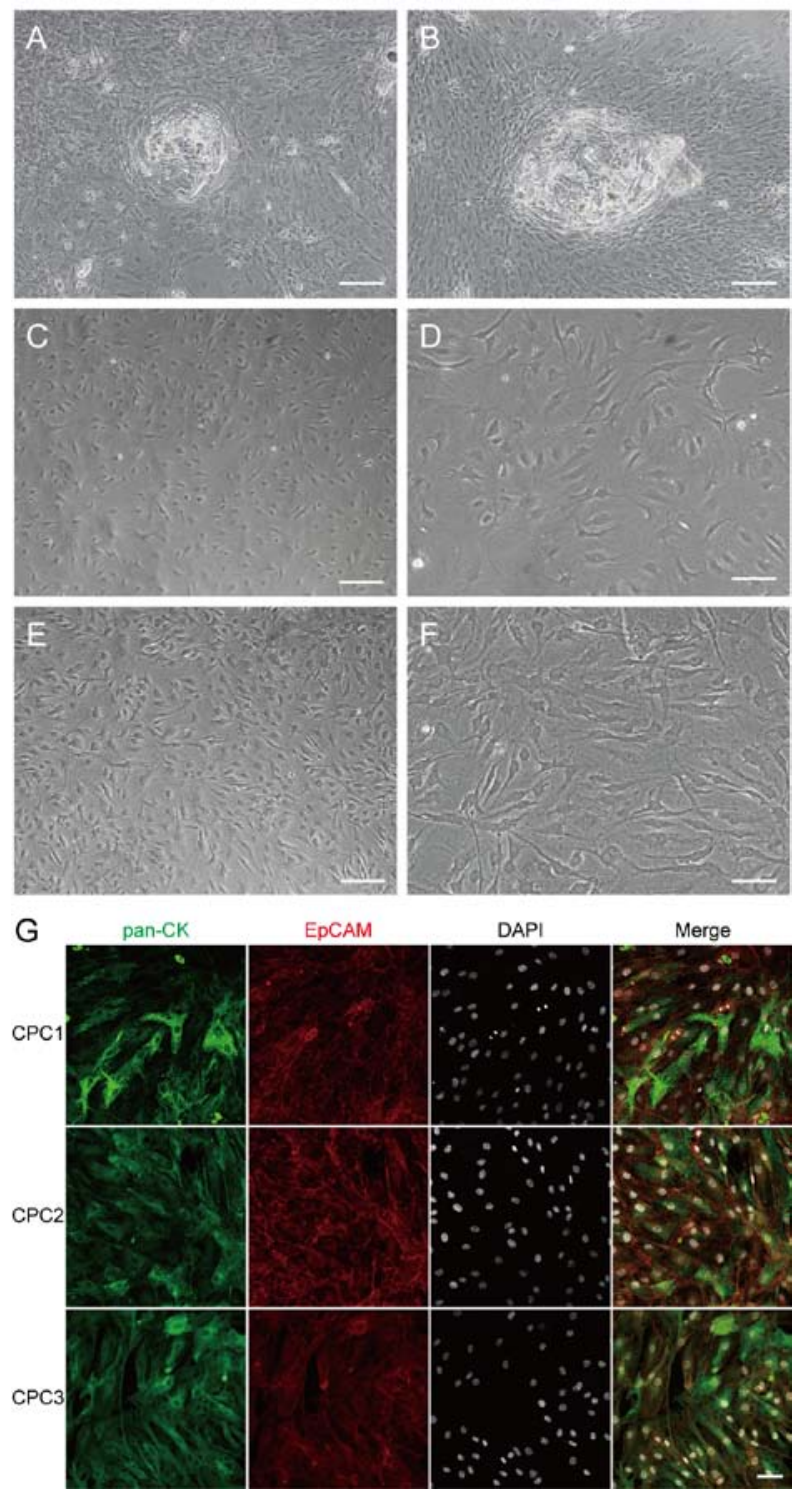

Figure 1. Morphology and lineage identification of primary cells. At the start of culture, primary cells exhibited paving stone-like appearance and spontaneously formed keratin pearls on (A) the second and (B) the third day of CPC culture. With the prolongation of culture time and passages, the morphology of cells gradually changed from the initial epithelial irregular polygon shape to spindle shape. (C) Cells in low density; magnification, x200. (D) Cells in low density; magnification, $\mathrm{x} 400$. (E) cells in high density; magnification, $\mathrm{x} 200$. (F) Cells in high density; magnification, x400. (G) Double immunostaining of long-term cultured CPCs (CPC1, CPC2 and CPC3) demonstrated that pan-CK and EpCAM remained positive with prolonged culture time, although cell morphology had changed. Scale bars: A, B, C and E, $100 \mu \mathrm{m}$; $\mathrm{D}, \mathrm{F}$ and G, $50 \mu \mathrm{m}$. CPCs, craniopharyngioma primary cells; CPC1, 10 days culture; $\mathrm{CPC} 2,20$ days culture; $\mathrm{CPC} 3,30$ days of culture; pan-CK, pan-cytokeratin; EpCAM, epithelial cell adhesion molecule.

Differential gene expression between ACP tissues and CPCs. Differentially expressed genes and samples were hierarchically clustered. The results suggested that ACP tumor tissues and CPCs were grouped into two categories (Fig. 3A), and they were represented by black and white. This indicated that the intra-group similarity between tumor tissues and primary cells was greater compared with the similarity between groups. To further analyze the differential gene expression between CPCs and ACP tissues, differential genes were screened using the standard criteria, including FPKM $>1$ and q-value $<0.05$. The 

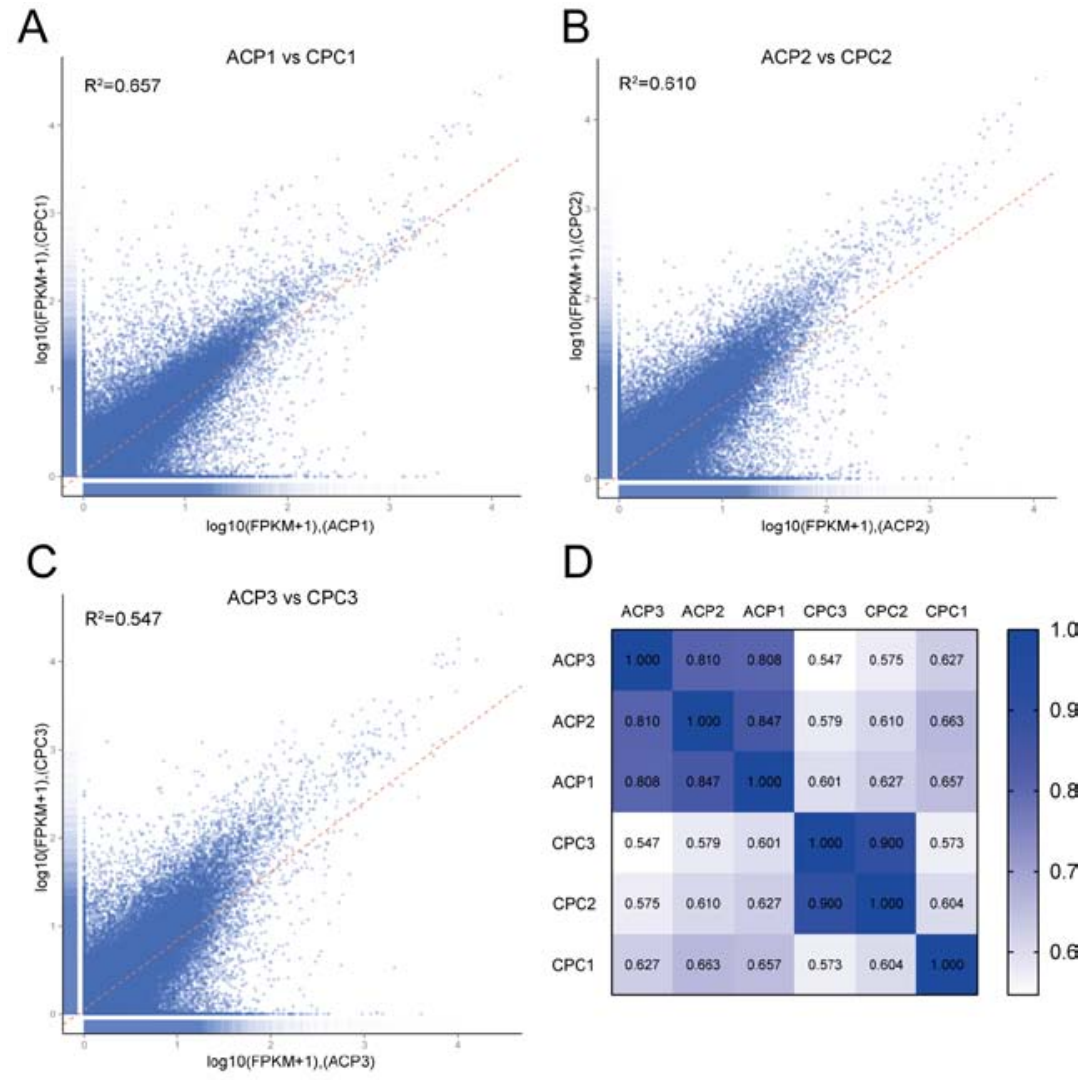

Figure 2. Consistency of transcriptome between ACP tissues and CPCs. With increasing culture time, the correlation coefficient of transcriptome between ACP tumors and CPCs gradually decreased. (A-C) Transcriptome correlation between tissues and cells at (A) 10, (B) 20 and (C) 30 days of culture. (D) The heatmap of the correlation coefficient was at a high level $(>0.8)$ among the three ACP tissues, whereas with increased culturing time, the correlation coefficient of transcriptome between ACP tissues and CPCs gradually decreased. Deeper blue represents stronger correlation. ACP1, 2 and 3 respectively represent tumor tissues used to culture CPC1, 2 and 3. ACP, adamantinomatous craniopharyngioma; CPCs, craniopharyngioma primary cells; CPC1, 10 days culture; CPC2, 20 days culture; CPC3, 30 days of culture; FPKMs, fragments per kilobase of exon per million fragments mapped.

results indicated that the number of differentially expressed genes was increased between ACP tissues and CPCs in a culture time-dependent manner; the number of differentially expressed genes (DEGs) was increased from 1,247 (CPC1) to 1,643 (CPC2) and further to 1,949 (CPC3). Compared with the ACP tissues, the number of upregulated genes in CPCs was 901 (CPC1), 1,359 (CPC2) and 1,453 (CPC3), whereas the number of downregulated genes was 346 (CPC1), 284 (CPC2) and 496 (CPC3) (Fig. 3B).

The transcriptome information for GSEA analysis was subsequently used to identify DEG sets between ACP tissues and CPC. The results showed that the diversity of gene sets between ACP tissues and CPCs increased with culture duration (FDR $<0.25 ; \mathrm{P}<0.01$ and $\mathrm{P}<0.05$ ). $\mathrm{DEG}$ sets increased from 19 to 203 and further to 405 under the criteria of FDR $<0.25$; DEG sets increased from 330 to 814 and then to 877 under $\mathrm{P}<0.01$, whereas DEG sets increased from 1,075 to 1,943 and then to 2,083 when $\mathrm{P}<0.05$ (Fig. 3C).

Similarities and differences between characteristic genes and gene sets in ACP tissues and CPCs. In order to illustrate the simulation potential of CPC models for ACP tissues, 20 ACP-characteristic genes were selected based on previous reports (9) and the differences in these genes between ACP tissues and CPCs were analyzed. The results demonstrated that the majority of the genes were not significantly differentially expressed in the tumors and cultured cells. No significant difference was observed in the expression of the following genes (tumors vs. primary cells): Amphiregulin [AREG; fold-change $(\mathrm{FC})=0.588 ; \mathrm{P}=0.734]$, a member of the epidermal growth factor family; epidermal growth factor receptor $(\mathrm{FC}=0.919 ; \mathrm{P}=0.705)$; $\mathrm{EPH}$ receptor $\mathrm{A} 2(\mathrm{FC}=0.638$; $\mathrm{P}=0.599$ ), which belongs to the ephrin receptor subfamily of the protein-tyrosine kinase family, and $M U C 1$ ( $\mathrm{FC}=0.512$; $\mathrm{P}=0.479$ ), encoded a membrane-bound protein for forming protective mucous barriers on epithelial surfaces. However, a number of significant gene changes were identified, including TNF superfamily member $11(\mathrm{FC}=21.99 ; \mathrm{P}=0.003), \mathrm{SRC}$ proto-oncogene $(\mathrm{FC}=1.352 ; \mathrm{P}=0.013)$, interleukin 2 receptor subunit $\beta(\mathrm{FC}=23.636 ; \mathrm{P}=0.009)$ and interleukin 6 receptor $(\mathrm{FC}=3.496 ; \mathrm{P}=0.035)$, which were involved in cell proliferation, differentiation and immune responses (Fig. 4A).

GSEA was performed for all samples and selected characteristic gene sets ('Wnt/ $\beta$-catenin pathway', 'Inflammation', 'TGF- $\beta$ pathway', 'EGF pathway', 'Shh pathway' and 'BMPs/FGFs') were selected for further analysis. No significant differences were observed between ACP tissues and CPCs in the majority of the characteristic gene sets (Fig. 4B-G). However, in CPC, the 'keratinization' [normalized enrichment score (NES)=-2.02, false discovery rate $(\mathrm{FDR})=0.0038]$ and 'epithelial cell proliferation' $(\mathrm{NES}=-1.82$, $\mathrm{FDR}=0.032$ ) phenotypes were significantly weakened. At the 


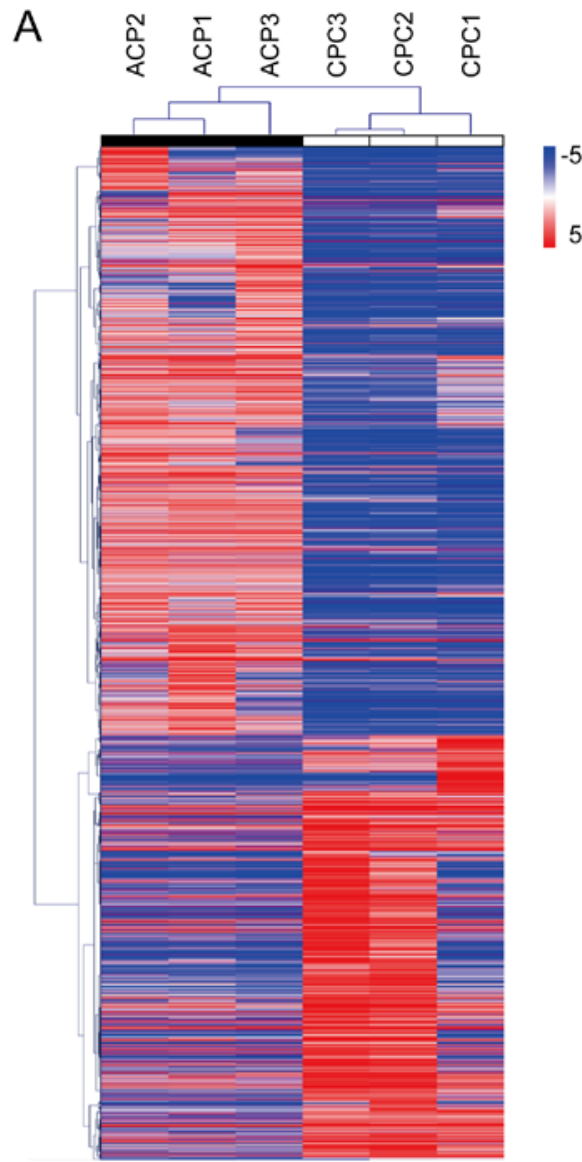

B
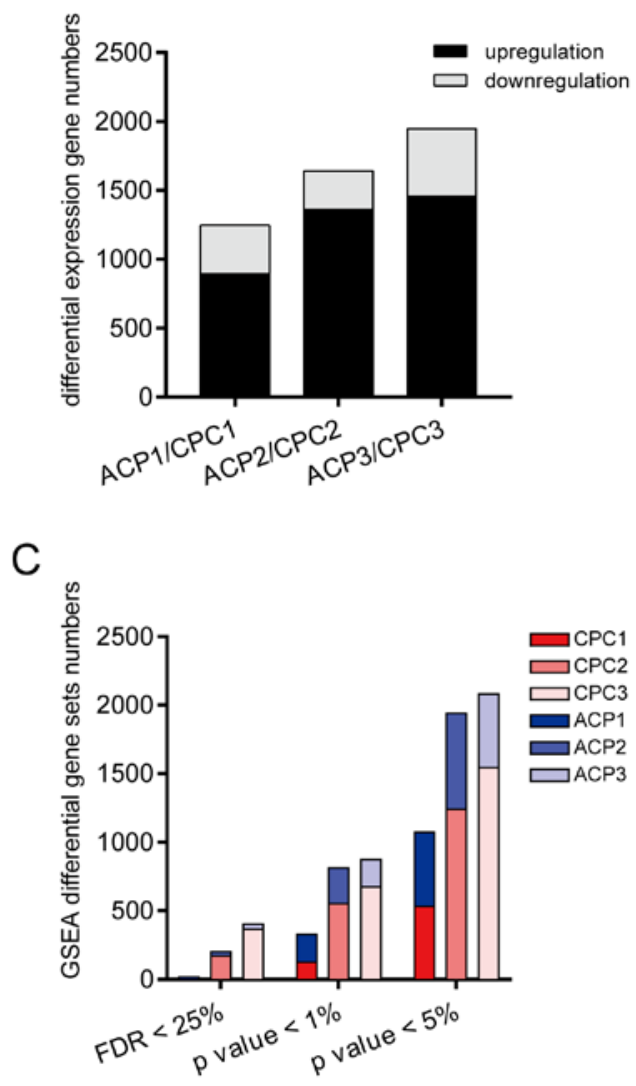

Figure 3. Description of differentially expressed genes and gene sets between tumor samples and primary cells. (A) Hierarchical clustering analysis of differential genes between ACP tissues and CPCs demonstrated that samples were divided into two categories. ACP tissues and CPCs are represented by black and white. (B) Comparison of differentially expressed genes between ACP tissues and CPCs. With the increase of culture duration, the number of differential genes increased significantly. (C) GSEA revealed that with prolonged incubation time, the diversity of gene sets between ACP tissues and CPCs also increased. ACP1, 2 and 3 respectively represent tumor tissues used to culture $\mathrm{CPC} 1,2$ and 3 . ACP, adamantinomatous craniopharyngioma; CPCs, craniopharyngioma primary cells; $\mathrm{CPC1}, 10$ days culture; $\mathrm{CPC}$, 20 days culture; CPC3, 30 days of culture; FPKMs, fragments per kilobase of exon per million fragments mapped; FDR, false discovery rate; GSEA, Gene Set Enrichment Analysis.

same time, cell proliferation- $(\mathrm{NES}=1.78, \mathrm{FDR}=0.028)$ and mitosis- (NES=1.93, FDR=0.012) associated phenotypes were significantly enhanced (Fig. 5A-H).

Western blot analysis of tumor tissues and primary cells after different culture times was used to detect the attenuation of primary cell epithelialization and keratinization phenotypes. Keratin 5, a marker of the keratinization phenotype, and E-cadherin, a marker of the epithelial phenotype, were significantly downregulated, whereas vimentin, a marker of the mesenchymal phenotype, was significantly upregulated in CPCs compared with APC tissues (Fig. 5I).

\section{Discussion}

Craniopharyngioma is a rare type of intracranial tumor $(1,4)$. The use of transgenic mouse models has resulted in breakthroughs in craniopharyngioma research $(10,25)$. Craniopharyngioma is a tumor with a low frequency of mutation, therefore transgenic mice modified to express the known $C T N N B 1$ gene mutation can be used to simulate human craniopharyngioma $(5,26-28)$. However, the animal model cannot fully simulate human craniopharyngioma considering species differences and complex clinical manifestations in patients, especially the multiple manifestations of hormonal abnormalities. Basic research into human craniopharyngioma has been progressing slowly in recent years, which may be due to the lack of a stable and accessible research platform for human ACP.

Craniopharyngioma is a benign tumor, and therefore it is challenging to produce a stable cell line; when the cells are not immortalized, the primary cells exhibit growth stagnation and trait changes in the late stage of in vitro culture. Primary cells are one of the most important research platforms at this stage (12). Whether primary cells can effectively simulate the tumor microenvironment remains unknown. The transcriptome represents the entire manifestation of RNA transcripts in cells or tissues and DEGs at various life stages, in different tissue types, physiological states and environmental conditions. Transcriptome analysis provides a comprehensive understanding of gene expression and its regulation (29). RNA-Seq is a powerful tool used for the comprehensive characterization of the whole transcriptome at both the gene and exon levels (30). RNA-Seq is based on next generation sequencing technology. Compared with traditional technology, which can only be used 
A

ACP signature gene expression

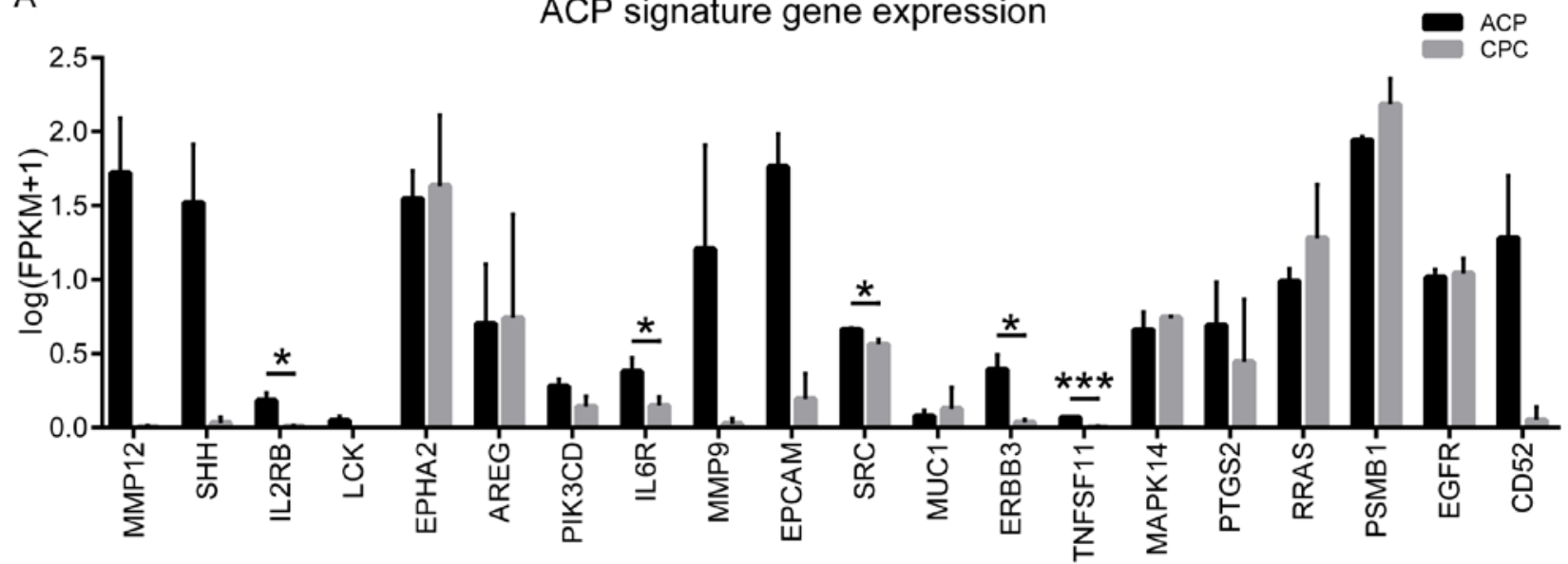

NES vs. significance of GSEA

- NOM p-value

- FDR q-value

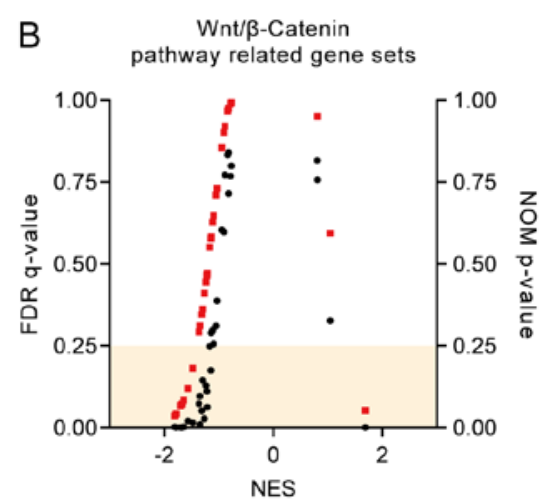

C $\quad \begin{gathered}\text { inflammation } \\ \text { related gene sets }\end{gathered}$

D $\begin{gathered}\text { TGF- } \beta \text { pathway } \\ \text { related gene sets }\end{gathered}$
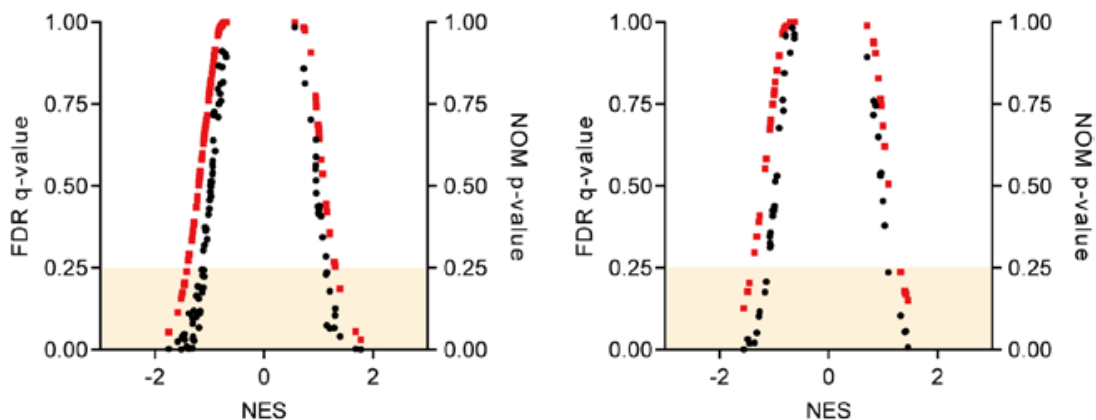

E

F

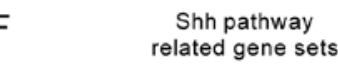

G
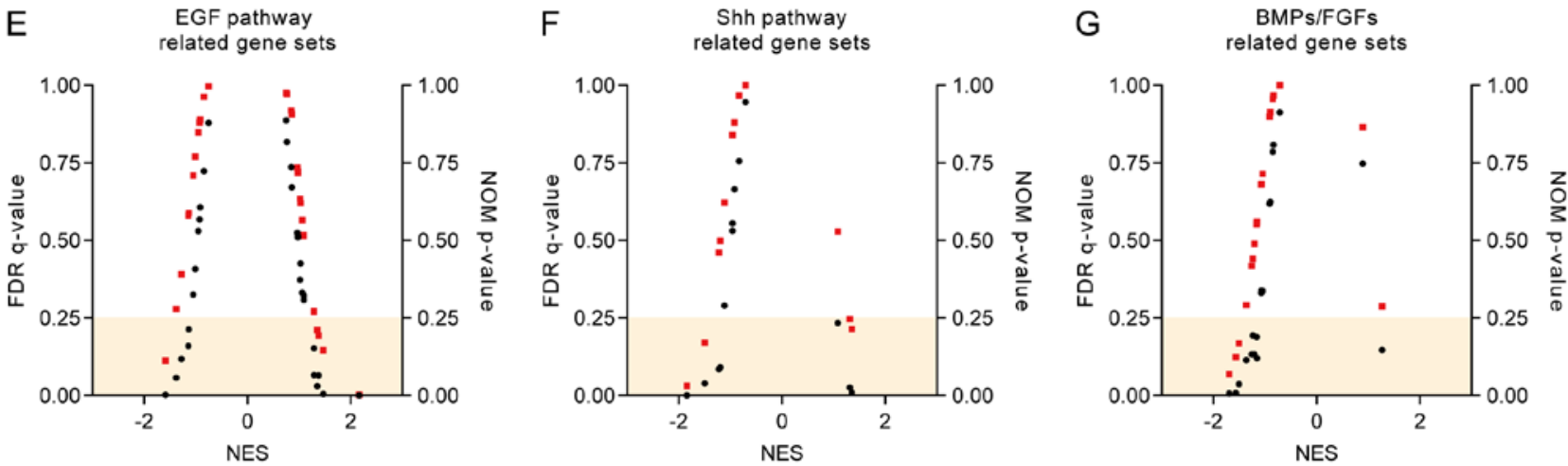

Figure 4. Description of differential characteristic genes and gene sets between ACP tissues and CPCs. (A) The majority of characteristic genes and possible therapeutic targets between ACP tissues and CPCs were not significantly different. (B-G) GSEA revealed that characteristic gene sets, including (B) 'Wnt/ $\beta$-catenin pathway', (C) 'Inflammation', (D) 'TGF- $\beta$ pathway', (E) 'EGF pathway', (F) 'Shh pathway' and (G) 'BMPs/FGFs' were not significantly different between ACP tissues and CPCs. "P<0.05 and ${ }^{* * * *} \mathrm{P}<0.001$. ACP, adamantinomatous craniopharyngioma; CPC, craniopharyngioma primary cells; FPKMs, fragments per kilobase of exon per million fragments mapped; NOM, nominal; FDR, false discovery rate; GSEA, Gene Set Enrichment Analysis; NES, normalized enrichment score; TGF- $\beta$, transforming growth factor- $\beta$; EGF, epidermal growth factor; Shh, Sonic hedgehog; BMPs, bone morphogenetic proteins; FGFs, fibroblast growth factors.

detect known genes, RNA-Seq is a cost-efficient technology that can detect almost all genes expressed in samples, including novel genes and dynamic changes in gene expression (31-34). RNA-Seq technology was used in this study to detect genetic differences between tumor samples and primary cells and to demonstrate whether primary cells can be used as a model for ACP research at the gene level.

Changes in the morphology and properties of CPCs were first compared following culture for different durations. The results revealed that the morphology of primary cells notably changed with increased culture time. The morphology of primary cells changed from an epithelial to a stromal state, but maintained original epithelial lineage markers, including pan-CK and EpCAM.

ACP tissues and CPCs were further analyzed using RNA-Seq analysis. To the best of our knowledge, this was the first time that transcriptome differences between ACP tissues and CPCs were analyzed using RNA-Seq. The results demonstrated that 

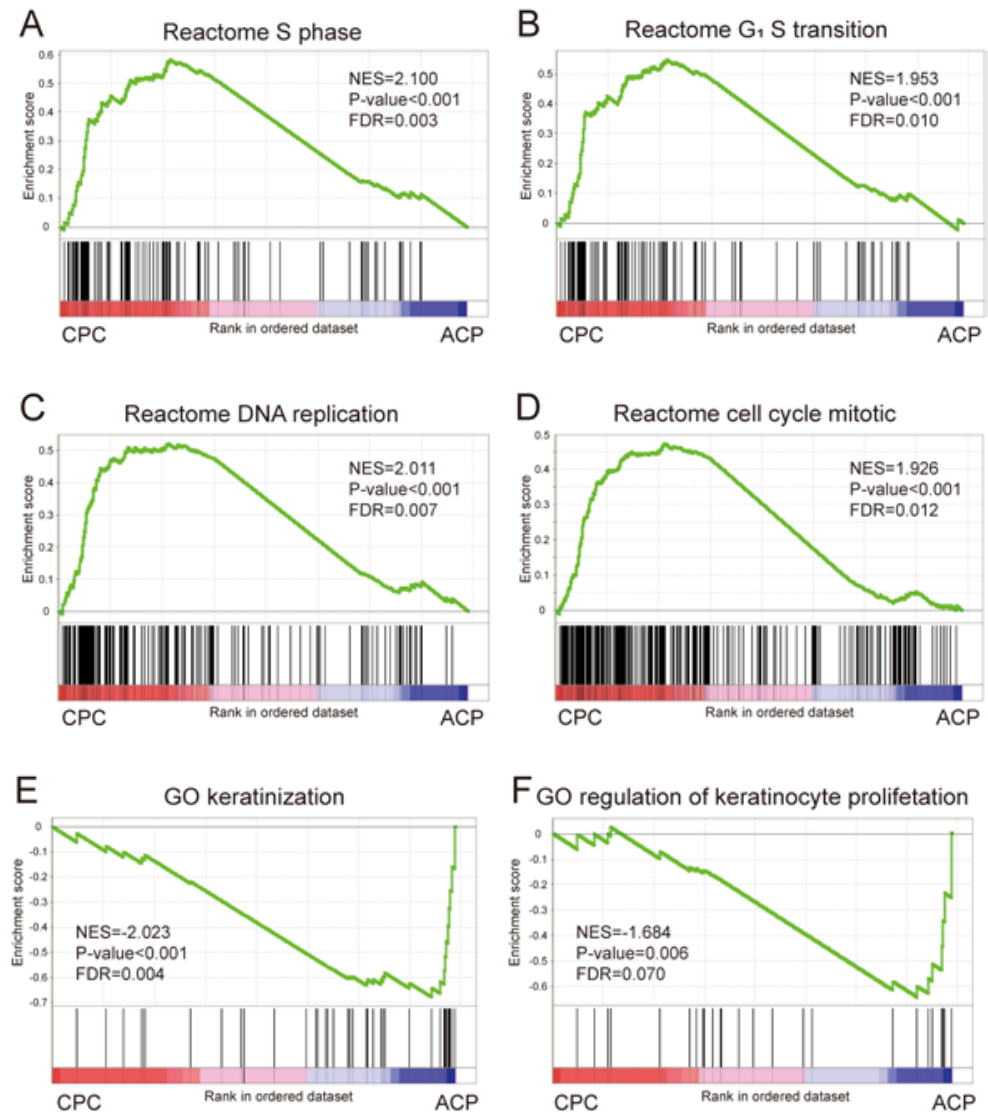

F GO regulation of keratinocyte prolifetation

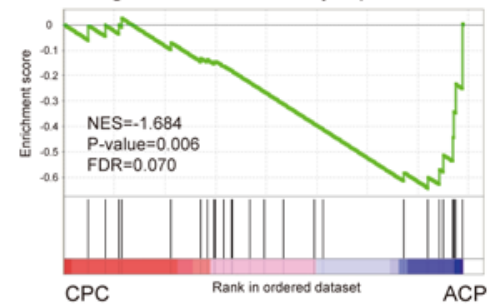

G GO epithelial cell proliferation

H GO morphogenesis of an epithelium
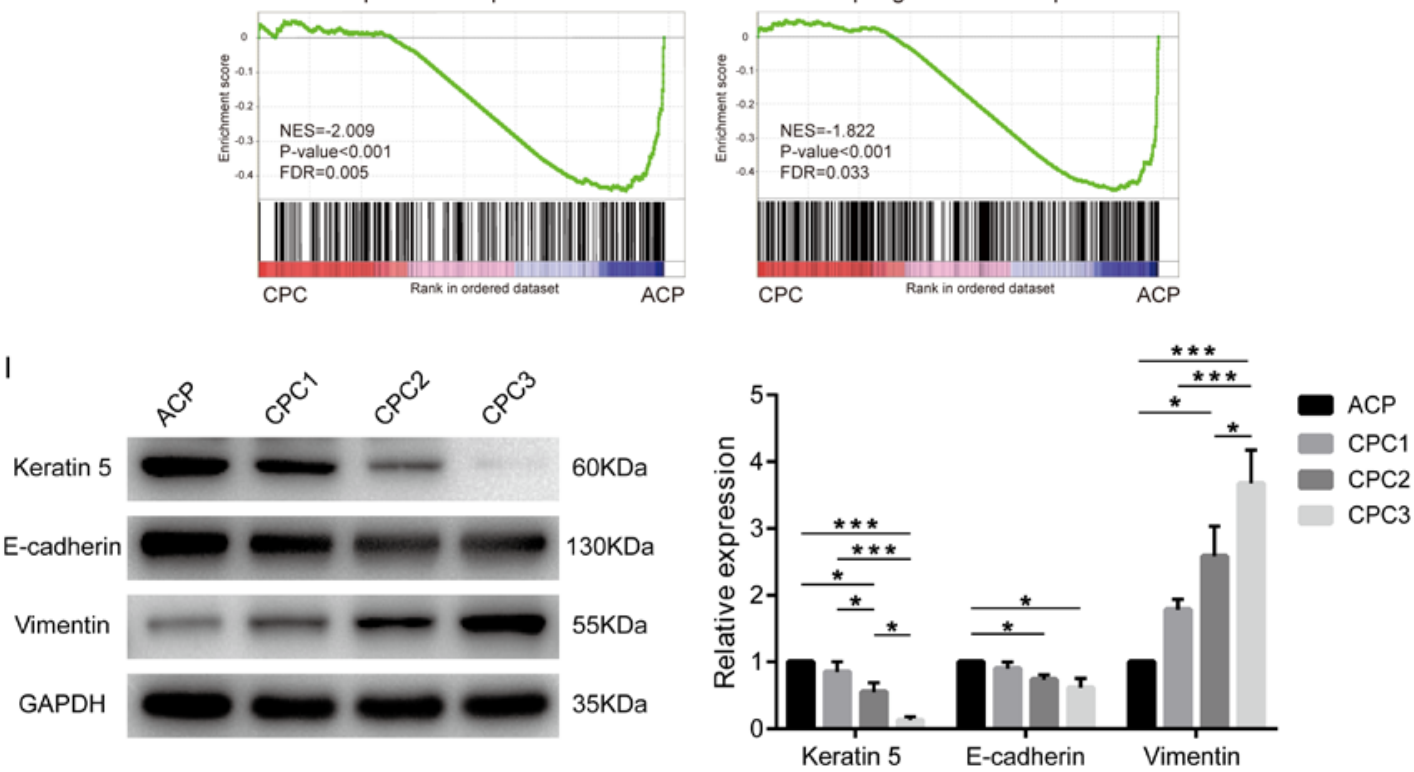

Figure 5. Significantly different gene sets between ACP tissues and CPCs. (A-D) GSEA results revealed that the gene sets associated with cell proliferation (A) $\mathrm{S}$ phase, (B) $\mathrm{G}_{1} / \mathrm{S}$ transition, (C) DNA replication and (D) cell cycle were significantly enriched in primary cells compared with ACP tissues. (E-H) The epithelial phenotype-associated gene sets (E) keratinization, $(\mathrm{F})$ regulation of keratinocyte proliferation, $(\mathrm{G})$ epithelial proliferation and $(\mathrm{H})$ morphogenesis of an epithelium decreased significantly in CPCs compared with ACP tissues. (I) Western blot analysis results suggested that with prolonged culture time, the marker of keratinization phenotype keratin 5 and the marker of epithelial phenotype E-cadherin were significantly downregulated, whereas the marker of mesenchymal phenotypes vimentin was significantly upregulated in CPCs compared with APC tissues. " $\mathrm{P}<0.05$ and ${ }^{* * *} \mathrm{P}<0.001$. GSEA, Gene Set Enrichment Analysis; GO, gene ontology; ACP, adamantinomatous craniopharyngioma; CPC, craniopharyngioma primary cells; CPC1, 10 days culture; CPC2, 20 days culture; $\mathrm{CPC} 3,30$ days of culture.

the correlation between tumor tissues and primary cell transcriptome gradually decreased with increased culture duration, whereas DEGs and GSEA-assembled differential gene sets gradually increased. However, the results suggested that the
CPCs resembled and maintained the overall genomic signatures of ACP tissues from which they were derived.

A number of studies have reported morphological and phenotypic changes in long-term cultured cells (35-37). This is 
consistent with the results of the present study. It was concluded that such changes were mainly associated with alternations in the tumor microenvironment. Hypoxia is likely to occur after long-term cell culture, resulting in hypoxia-inducible factor $1 \alpha$ upregulation and the subsequent activation of a series of pathways, including the AKT/PI3K and the transforming growth factor- $\beta 1 /$ SMAD pathways. This activation may contribute to the occurrence of epithelial-mesenchymal transition. These pathways may also lead to enhanced invasive and proliferative capacities with reduced apoptosis in long-term cultured cells.

In summary, ACP primary cells may be used as a suitable research platform; however, the relevant experiments should be concluded as early as possible to maintain consistency between primary cells and tumor tissues. The recommended in vitro culture time should be $<30$ days to ensure that the primary cell model is representative of tumor tissues. However, the present study is not without limitations. The sample size was small and thus the number of cases included in this experiment is insufficient. In future studies, larger sample sizes should be used and in vivo experiments should be performed to confirm the present results of the present study.

\section{Acknowledgements}

Not applicable.

\section{Funding}

This study was supported by grants from Science and Technology Program of Guangdong (grant nos. 2016A020213006, 2017A020215048 and 2017A020215191); Natural Science Foundation of Guangdong (grant no. 2016A030310377); Science and Technology Program of Guangzhou (grant no. 201707010149); President Foundation of Nanfang Hospital, Southern Medical University (grant nos. 2015C018, 2016L002 and 2017Z009).

\section{Availability of data and materials}

The datasets used and/or analyzed during the present study are available from the corresponding author on reasonable request.

\section{Authors' contributions}

SQ contributed to experimental design. $\mathrm{PZ}$ and $\mathrm{CW}$ performed the experiments. PZ and YL performed the bioinformatics analysis on RNA sequencing data. CW carried out the immunostaining analysis. YL, JF, JXP and JP contributed to the pathological analysis of human samples. YL and JP wrote the manuscript.

\section{Ethics approval and consent to participate}

Written informed consent was provided by all subjects in accordance with the Declaration of Helsinki. The present study was approved by the local Ethics Committee of Nanfang Hospital, Southern Medical University.

\section{Patient consent for publication}

Not applicable.

\section{Competing interests}

The authors declare that they have no competing interests.

\section{References}

1. Erfurth EM, Holmer H and Fjalldal SB: Mortality and morbidity in adult craniopharyngioma. Pituitary 16: 46-55, 2013.

2. Olsson DS, Andersson E, Bryngelsson IL, Nilsson AG and Johannsson G: Excess mortality and morbidity in patients with craniopharyngioma, especially in patients with childhood onset: A population-based study in Sweden. J Clin Endocrinol Metab 100: 467-474, 2015.

3. Tomlinson JW, Holden N, Hills RK, Wheatley K, Clayton RN, Bates AS, Sheppard MC and Stewart PM: Association between premature mortality and hypopituitarism. West midlands prospective hypopituitary study group. Lancet 357: 425-431, 2001.

4. Muller HL, Merchant TE, Puget S and Martinez-Barbera JP: New outlook on the diagnosis, treatment and follow-up of childhood-onset craniopharyngioma. Nat Rev Endocrinol 13: 299-312, 2017.

5. Brastianos PK, Taylor-Weiner A, Manley PE, Jones RT, Dias-Santagata D, Thorner AR, Lawrence MS, Rodriguez FJ, Bernardo LA, Schubert L, et al: Exome sequencing identifies BRAF mutations in papillary craniopharyngiomas. Nat Genet 46: 161-165, 2014.

6. Kato K, Nakatani Y, Kanno H, Inayama Y, Ijiri R, Nagahara N, Miyake T, Tanaka M, Ito Y, Aida N, et al: Possible linkage between specific histological structures and aberrant reactivation of the Wnt pathway in adamantinomatous craniopharyngioma. J Pathol 203: 814-821, 2004.

7. Sekine S, Shibata T, Kokubu A, Morishita Y, Noguchi M, Nakanishi Y, Sakamoto M and Hirohashi S: Craniopharyngiomas of adamantinomatous type harbor beta-catenin gene mutations. Am J Pathol 161: 1997-2001, 2002.

8. Hölsken A, Sill M, Merkle J, Schweizer L, Buchfelder M, Flitsch J, Fahlbusch R, Metzler M, Kool M, Pfister SM, et al: Adamantinomatous and papillary craniopharyngiomas are characterized by distinct epigenomic as well as mutational and transcriptomic profiles. Acta Neuropathol Commun 4: 20, 2016.

9. Gump JM, Donson AM, Birks DK, Amani VM, Rao KK, Griesinger AM, Kleinschmidt-DeMasters BK, Johnston JM, Anderson RC, Rosenfeld A, et al: Identification of targets for rational pharmacological therapy in childhood craniopharyngioma. Acta Neuropathol Commun 3: 30, 2015.

10. Andoniadou CL, Matsushima D, Mousavy Gharavy SN, Signore M, Mackintosh AI, Schaeffer M, Gaston-Massuet C, Mollard P, Jacques TS, Le Tissier P, et al: Sox2(+) stem/progenitor cells in the adult mouse pituitary support organ homeostasis and have tumor-inducing potential. Cell Stem Cell 13: 433-445, 2013.

11. Gaston-Massuet C, Andoniadou CL, Signore M, Jayakody SA, Charolidi N, Kyeyune R, Vernay B, Jacques TS, Taketo MM, Le Tissier P, et al: Increased Wingless (Wnt) signaling in pituitary progenitor/stem cells gives rise to pituitary tumors in mice and humans. Proc Natl Acad Sci USA 108: 11482-11487, 2011.

12. Hölsken A and Buslei R: Models of human adamantinomatous craniopharyngioma tissue: Steps toward an effective adjuvant treatment. Brain Pathol 27: 358-363, 2017.

13. Hölsken A, Buchfelder M, Fahlbusch R, Blümcke I and Buslei R: Tumour cell migration in adamantinomatous craniopharyngiomas is promoted by activated Wnt-signalling. Acta Neuropathol 119: 631-639, 2010.

14. Chen M, Zheng SH, Liu Y, Shi J and Qi ST: Periostin activates pathways involved in epithelial-mesenchymal transition in adamantinomatous craniopharyngioma. J Neurol Sci 360: 49-54, 2016.

15. Liu Y, Wang CH, Li DL, Zhang SC, Peng YP, Peng JX, Song Y, Qi ST and Pan J: TREM-1 expression in craniopharyngioma and Rathke's cleft cyst: Its possible implication for controversial pathology. Oncotarget 7: 50564-50574, 2016.

16. Langmead B and Salzberg SL: Fast gapped-read alignment with Bowtie 2. Nat Methods 9: 357-359, 2012.

17. Pertea M, Kim D, Pertea GM, Leek JT and Salzberg SL: Transcript-level expression analysis of RNA-seq experiments with HISAT, StringTie and Ballgown. Nat Protoc 11: 1650-1667, 2016.

18. Kim D, Langmead B and Salzberg SL: HISAT: A fast spliced aligner with low memory requirements. Nat Methods 12: 357-360, 2015. 
19. Pertea M, Pertea GM, Antonescu CM, Chang TC, Mendell JT and Salzberg SL: StringTie enables improved reconstruction of a transcriptome from RNA-seq reads. Nat Biotechnol 33: 290-295, 2015.

20. Trapnell C, Williams BA, Pertea G, Mortazavi A, Kwan G, van Baren MJ, Salzberg SL, Wold BJ and Pachter L: Transcript assembly and quantification by RNA-Seq reveals unannotated transcripts and isoform switching during cell differentiation. Nat Biotechnol 28: 511-515, 2010.

21. Frazee AC, Sabunciyan S, Hansen KD, Irizarry RA and Leek JT: Differential expression analysis of RNA-seq data at single-base resolution. Biostatistics 15: 413-426, 2014.

22. Mootha VK, Lindgren CM, Eriksson KF, Subramanian A, Sihag S, Lehar J, Puigserver P, Carlsson E, Ridderstråle M, Laurila E, et al: PGC-1alpha-responsive genes involved in oxidative phosphorylation are coordinately downregulated in human diabetes. Nat Genet 34: 267-273, 2003.

23. Subramanian A, Tamayo P, Mootha VK, Mukherjee S, Ebert BL, Gillette MA, Paulovich A, Pomeroy SL, Golub TR, Lander ES and Mesirov JP: Gene set enrichment analysis: A knowledge-based approach for interpreting genome-wide expression profiles. Proc Natl Acad Sci USA 102: 15545-15550, 2005

24. Thimsen V, Hölsken A, Buchfelder M, Flitsch J, Fahlbusch R, Stefanits H, Losa M, Jones DT and Buslei R: EpCAM (CD326) is differentially expressed in craniopharyngioma subtypes and Rathke's cleft cysts. Sci Rep 6: 29731, 2016.

25. Gonzalez-Meljem JM, Haston S, Carreno G, Apps JR, Pozzi S, Stache C, Kaushal G, Virasami A, Panousopoulos L, Mousavy-Gharavy SN, et al: Stem cell senescence drives age-attenuated induction of pituitary tumours in mouse models of paediatric craniopharyngioma. Nat Commun 8: 1819, 2017.

26. Campanini ML, Colli LM, Paixao BM, Cabral TP, Amaral FC Machado HR, Neder LS, Saggioro F, Moreira AC, Antonini SR and de Castro M: CTNNB1 gene mutations, pituitary transcription factors, and MicroRNA expression involvement in the pathogenesis of adamantinomatous craniopharyngiomas. Horm Cancer 1: 187-196, 2010.

27. Sekine S, Sato S, Takata T, Fukuda Y, Ishida T, Kishino M, Shibata T, Kanai Y and Hirohashi S: Beta-catenin mutations are frequent in calcifying odontogenic cysts, but rare in ameloblastomas. Am J Pathol 163: 1707-1712, 2003

28. Hölsken A, Kreutzer J, Hofmann BM, Hans V, Oppel F, Buchfelder M, Fahlbusch R, Blümcke I and Buslei R: Target gene activation of the Wnt signaling pathway in nuclear beta-catenin accumulating cells of adamantinomatous craniopharyngiomas. Brain Pathol 19: 357-364, 2009.
29. van Dijk EL, Auger H, Jaszczyszyn Y and Thermes C: Ten years of next-generation sequencing technology. Trends Genet 30: 418-426, 2014.

30. Foo JN, Liu JJ and Tan EK: Whole-genome and whole-exome sequencing in neurological diseases. Nat Rev Neurol 8: 508-517, 2012.

31. Pickrell JK, Marioni JC, Pai AA, Degner JF, Engelhardt BE, Nkadori E, Veyrieras JB, Stephens M, Gilad Y and Pritchard JK: Understanding mechanisms underlying human gene expression variation with RNA sequencing. Nature 464: 768-772, 2010.

32. Wang Z, Gerstein M and Snyder M: RNA-Seq: A revolutionary tool for transcriptomics. Nat Rev Genet 10: 57-63, 2009.

33. Byron SA, Van Keuren-Jensen KR, Engelthaler DM, Carpten JD and Craig DW: Translating RNA sequencing into clinical diagnostics: Opportunities and challenges. Nat Rev Genet 17: 257-271, 2016.

34. Jeppesen M, Hagel G, Glenthoj A, Vainer B, Ibsen P, Harling H, Thastrup O, Jørgensen LN and Thastrup J: Short-term spheroid culture of primary colorectal cancer cells as an in vitro model for personalizing cancer medicine. PLoS One 12: e0183074, 2017.

35. Mahajan AS, Sugita BM, Duttargi AN, Saenz F, Krawczyk E, McCutcheon JN, Fonseca AS, Kallakury B, Pohlmann P, Gusev Y and Cavalli LR: Genomic comparison of early-passage conditionally reprogrammed breast cancer cells to their corresponding primary tumors. PLoS One 12: e0186190, 2017.

36. Broutier L, Mastrogiovanni G, Verstegen MM, Francies HE, Gavarró LM, Bradshaw CR, Allen GE, Arnes-Benito R, Sidorova O, Gaspersz MP, et al: Human primary liver cancer-derived organoid cultures for disease modeling and drug screening. Nat Med 23: 1424-1435, 2017.

37. Mortazavi A, Williams BA, McCue K, Schaeffer L and Wold B: Mapping and quantifying mammalian transcriptomes by RNA-Seq. Nat Methods 5: 621-628, 2008.

c) () $\ominus$ This work is licensed under a Creative Commons Attribution-NonCommercial-NoDerivatives 4.0 International (CC BY-NC-ND 4.0) License. 